Article

\title{
Thermal Stability of Hexamethyldisiloxane (MM) for High-Temperature Organic Rankine Cycle (ORC) ${ }^{\dagger}$
}

\author{
Markus Preißinger * and Dieter Brüggemann \\ Institute of Engineering Thermodynamics (LTTT), Center of Energy Technology (ZET), University of Bayreuth, \\ Bayreuth 95440, Germany; 1ttt@uni-bayreuth.de \\ * Correspondence: markus.preissinger@uni-bayreuth.de; Tel.: +49-921-55-7285 \\ + The original paper was presented in: Preißinger, M.; Brüggemann, D. Thermal stability of \\ hexamethyldisiloxane (MM) for high temperature applications. Lemort, V., Quoilin, S., De Paepe, M., \\ Van Den Broek, M., Eds. In Proceedings of the 3rd International Seminar on ORC Power Systems, \\ ASME-ORC 2015, Brussels, Belgium, 12-14 October 2015. ISBN:978-2-9600059-2-9.
}

Academic Editor: Sylvain Quoilin

Received: 19 January 2016; Accepted: 29 February 2016; Published: 10 March 2016

\begin{abstract}
The design of efficient Organic Rankine Cycle (ORC) units for the usage of industrial waste heat at high temperatures requires direct contact evaporators without intermediate thermal oil circuits. Therefore, the thermal stability of high-temperature working fluids gains importance. In this study, the thermal degradation of hexamethyldisiloxane (MM) is investigated in an electrically heated tube. Qualitative results concerning remarks on degradation products as well as quantitative results like the annual degradation rate are presented. It is shown that $\mathrm{MM}$ is stable up to a temperature of $300{ }^{\circ} \mathrm{C}$ with annual degradation rates of less than 3.5\%. Furthermore, the break of a silicon-carbon bond can be a main chemical reaction that influences the thermal degradation. Finally, it is discussed how the results may impact the future design of ORC units.
\end{abstract}

Keywords: organic Rankine cycle (ORC); thermal stability; degradation; hexamethyldisiloxane (MM); siloxane; high-temperature; waste heat recovery

\section{Introduction}

The Organic Rankine cycle (ORC) have been extensively used in biomass fired power plants. Due to the high temperature of the firing, an intermediate thermal oil circuit is used to prevent the organic working fluid from degradation [1-3]. Mostly, synthetic oils with degradation temperatures of more than $300{ }^{\circ} \mathrm{C}$ [4] are used to avoid thermal stress of the ORC working fluid. However, in the last years, ORC has become popular in other high-temperature applications as well. Especially, waste heat recovery from industrial processes and from diesel engines in stationary applications and heavy duty trucks are discussed. Linear siloxanes like hexamethyldisiloxane (MM) are promising working fluids for such high-temperature applications. However, a trend is noticed to direct contact evaporators without thermal oil circuit. The advantages are higher efficiencies, lower investment costs and a much simpler system design. Furthermore, for waste heat recovery in heavy duty trucks, the engine compartment package is crucial and mostly does not allow an additional circuit.

Although evaporation temperatures of MM are limited to a value below $240{ }^{\circ} \mathrm{C}$ for typical working pressures of about 17 bar, the film temperature at the heat exchanger surface, hot-spots within the heat exchanger and the failure mode have to be kept in mind (failure mode is e.g., a standstill of the ORC pump without shutdown of the heat source). Yang et al. [5,6] report temperatures of up to $547^{\circ} \mathrm{C}$ for engine exhaust gas and, depending on the load of the engine, up to $400 \mathrm{~K}$ temperature difference between the exhaust gas and the organic working fluid R461A. Zhang et al. [7] also report temperature beyond $527^{\circ} \mathrm{C}$ for the exhaust gas. A bottoming-cycle for a gas turbine is evaluated 
by Camporeale et al. [8] where the temperature is around $377^{\circ} \mathrm{C}$. To withstand these temperatures, an appropriate design of the evaporator is crucial. Chowdhury et al. [9] model an evaporator for waste heat recovery in which the heat source temperature varies by more than $100 \mathrm{~K}$ during operation. Guillen et al. [10] and Bei et al. [11] also develop direct contact evaporators for high temperatures. Weith et al. [12] investigate heat transfer characteristics of siloxanes including MM which are necessary for accurate heat exchanger design.

Furthermore, to use MM in a wide range of heat source temperatures, reliable data for its thermal stability are essential. The importance of thermal stability of the working fluid for high-temperature applications is highlighted by Colonna et al. [13] stating that this characteristic is still a remarkable deficit of most organic fluids compared to water as working fluid. However, water suffers from other drawbacks like high pressures, necessary superheating and low efficiency below a heat source temperature of $400{ }^{\circ} \mathrm{C}$. Although special working fluids like a mixture of $60 \mathrm{~mol} \%$ pentafluorobenzene and $40 \mathrm{~mol} \%$ hexafluorobenzene reached thermal stability until temperatures of up to $468^{\circ} \mathrm{C}$ [14], commonly used working fluids like siloxanes show significant degradation in long-term monitoring of real power plants [15]. Colonna et al. [16] report a limit of $400{ }^{\circ} \mathrm{C}$ for siloxanes, however, the duration of the experiments, the heating rate and the pressure remain unclear. For cyclic siloxanes, Angelino [17] gives a similar value of $400{ }^{\circ} \mathrm{C}$. Dvornic [18,19] investigates extensively thermal properties of polysiloxanes, however, he does not give quantitative results for the degradation temperature of MM.

To attain such results, different methodologies concerning design of the test rig and evaluation method are found in literature. Ginosar et al. [20] report a method to separate catalytic from thermal effects within a glass tube. The standard test procedure for the thermal stability of refrigerants is carried out almost similar [21]. For the same chemical class, the method of adiabatic compression is used to avoid the thermal degradation at hot surfaces [22]. Thermogravimetric analyses within vacuum [23-26] as well as the analysis of different catalysts [27] are also widespread. A test rig designed especially for measurements of ORC working fluids, and in particular of methylbenzenes, is reported by Angelino et al. [28]. Calderazzi and Colonna [29] use a similar test rig for different refrigerants. In both cases, the sample is located in a metallic cylinder and heated in an oven. Based on isothermal long-time experiments, the degradation rate is calculated. Cyclopentane, isopentane, n-butane and pentafluorohexane have also been investigated in a muffle furnace [30,31].

In the present study, a redesign of test rig of Angelino et al. [28] has been done using an electrical heated tube, which allows for high and accurately controlled heating rates. The main objective is to gain more knowledge on the influence of the working fluid temperature as well as the duration of the experiment. Furthermore, knowledge about the chemical composition of the degradation products is of main interest for a secure operation of direct contact evaporators for ORC systems.

\section{Methodology}

\subsection{Test Rig and Experimental Procedure}

A stainless steel tube with a length of $220 \mathrm{~mm}$ and an outer diameter of $18 \mathrm{~mm}$ is electrically heated according to Figure 1. The volume of the reactor accounts for $70.2 \mathrm{~mL}$. The power of the heating wire is $850 \mathrm{~W}$ on a length of $5 \mathrm{~m}$ allowing a continuous and uniform heating of up to $450{ }^{\circ} \mathrm{C}$. Compared to heating in an oven, faster heating rates are achieved and the heating rate can be chosen constant for all tests. Within a second tube with an outer diameter of $3 \mathrm{~mm}$ the temperature within the reactor is measured with a thermocouple and used as pre-set temperature for the isothermal test procedure. The reactor volume is flushed with nitrogen and evacuated two times before each test. This ensures constant test conditions for all samples. The vacuum pump has a pressure limit of $1.0 \times 10^{-6}$ bar. Therefore, the remaining mass of nitrogen in the reactor is negligible. A sample mass of about $7 \mathrm{~g}$ is fed into the reactor through the filling valve at the bottom of the tube. Afterwards, the reactor is sealed through blind plugs andheated until the preset temperature. The constant heating rate is chosen to $0.3 \mathrm{~K} / \mathrm{s}$. 
Subsequently, the time measurement starts. After the test period, the electrical heating is switched off and the reactor is cooled down to ambient temperature through natural convection. Subsequently, the analysis of the time-dependent temperature and pressure curves as well as the analysis of vapor and liquid phase by means of gas chromatography, mass spectroscopy and Karl-Fischer-titration is carried out. The raw material is MM with a purity of $97 \%$ from the company Wacker Chemie in Burghausen, Germany (Wacker®AK 0.65).

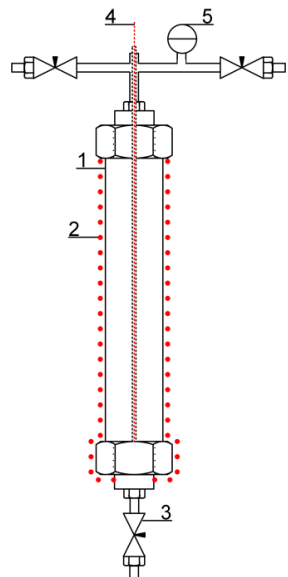

(a)

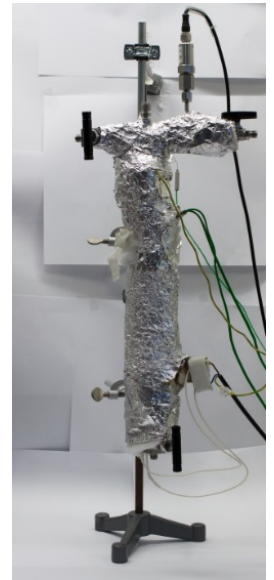

(b)

Figure 1. (a) Scheme of the reactor including stainless steel tube (1), electrical heating wire (2), needle valve (3), thermocouple (4) and pressure sensor (5); and (b) reactor in the lab.

\subsection{Evaluation Method}

To describe the evaluation method, an experiment with a temperature of $420{ }^{\circ} \mathrm{C}$ and duration of $72 \mathrm{~h}$ is selected exemplarily.

First of all, the heating period is analyzed. Figure 2a shows the pressure within the tube depending on temperature. The characteristic progression of the bubble line is obtained until a pressure of about 10 bar. However, due to the fact that the heating is much faster than the mixing of the fluid within the reactor, the vapor pressure at a specific temperature is lower than expected. Afterwards, the slope of the curve drops as the specific volume of MM within the reactor is higher than the critical specific volume [32]. Due to the subsequent full mixing within the reactor, the pressure increases marginally at a constant temperature of $420^{\circ} \mathrm{C}$. The slightly right-bending part between $120^{\circ} \mathrm{C}$ and $160^{\circ} \mathrm{C}$ is caused by contaminants within the raw material.

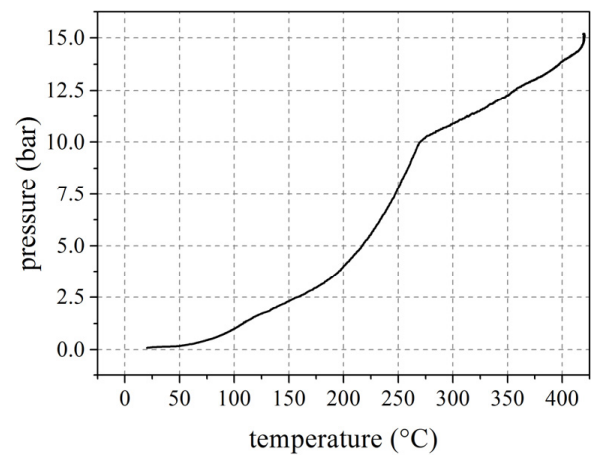

(a)

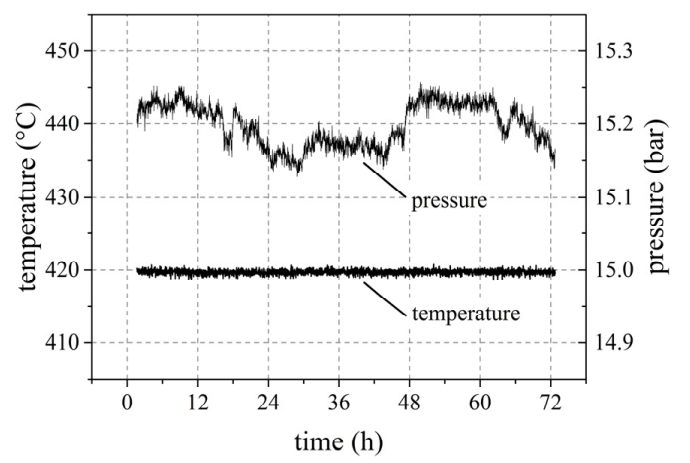

(b)

Figure 2. Experiment with a temperature of $420^{\circ} \mathrm{C}$ and a duration of $72 \mathrm{~h}$ : (a) pressure depending on temperature during heating period; and $(\mathbf{b})$ temperature and pressure depending on time. 
Secondly, the pressure profile during the isothermal test period in Figure $2 b$ shows a value of 15.2 bar with a fluctuation range of 0.05 bar. The pressure changes indicate the formation of molecules with lower or higher molecular mass. The noise signal of the pressure sensor ( \pm 5 mbar) does not affect the result. As the pressure changes are not clearly pronounced, further evaluation methods are needed.

The comparison of the pressure in the reactor before and after the experiment (Figure 3a,b) confirms the formation of molecules with lower molecular mass than MM. At a constant temperature and a fixed volume of the reactor, the pressure after the experiment is much higher than before, which is caused by high vapor pressure of the degradation products.

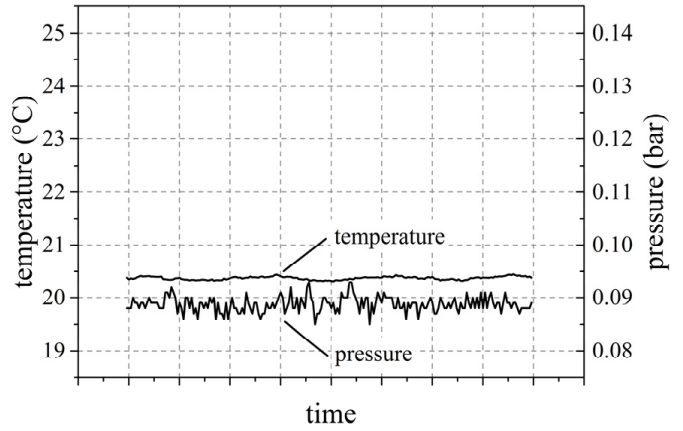

(a)

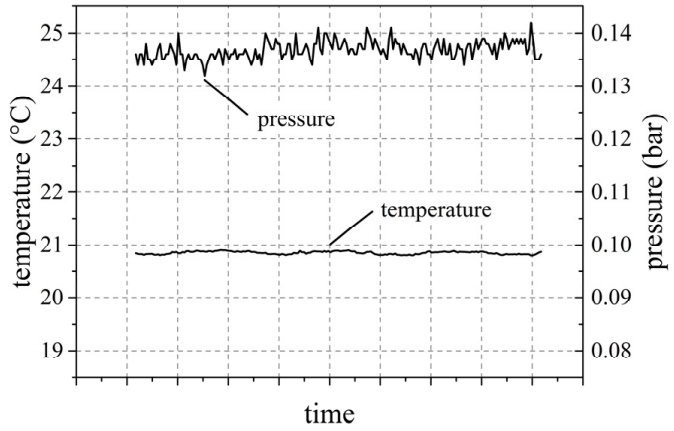

(b)

Figure 3. Experiment with a temperature of $420^{\circ} \mathrm{C}$ and a duration of $72 \mathrm{~h}$ : (a) temperature and pressure before the experiment; and (b) temperature and pressure after the experiment.

The chemical analysis of the products and the raw material by means of gas chromatography proves the assumption of low molecular substances. The mean relative error caused by the gas chromatograph is lower that $2 \%$. All components with a mass fraction higher than $0.4 \%$ in the vapor phase are displayed in Figure 4. The mass fraction of MM drops to 58\%. The main degradation products are low molecular hydrocarbons. This confirms the results from laser impulse experiments by Manders and Bellama [33]. Within the liquid phase traces of high molecular siloxanes are measured which fits the theory of Dvornic $[18,19]$. However, the mass fraction of MM within the liquid phase still exceeds $99 \%$ and indicates that the degradation products are mainly found in the vapor phase. As water catalyzes the thermal degradation of many organic compounds, the water content of the raw material is measured by means of Karl-Fischer titration, which gives a marginal value of $140 \mathrm{ppm}$. Furthermore, the nitrogen-flushing of the reactor and the subsequent evacuation ensures that hardly no free water or contaminants remain within the tube which would influence the experiments.

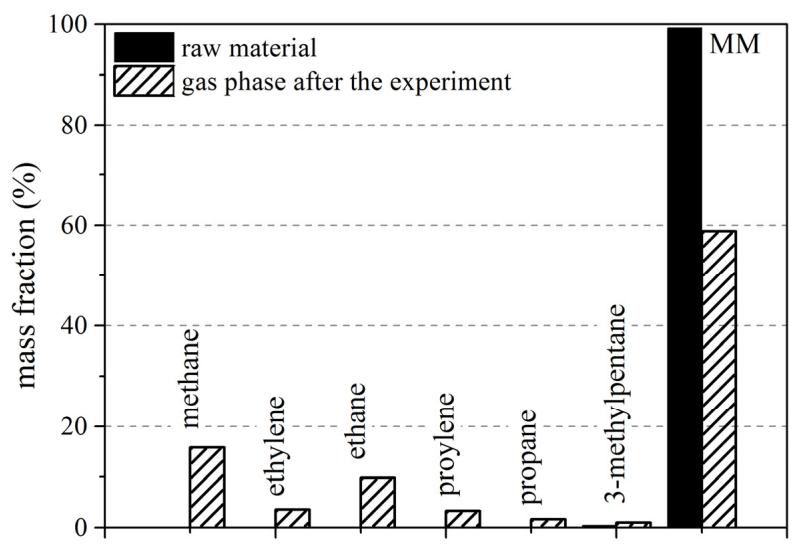

Figure 4. Mass fraction of vapor phase after the experiment and of raw material $\left(T=420^{\circ} \mathrm{C}, t=72 \mathrm{~h}\right.$, relative error caused by gas chromatograph $<2 \%$ ). 


\section{Discussion}

\subsection{Influence of Temperature on Thermal Degradation}

The influence of temperature on the thermal degradation is evaluated in Figure 5. The mass fraction of $\mathrm{MM}$ drops with increasing temperature. Below a temperature of $300{ }^{\circ} \mathrm{C}$, methane is the dominant degradation product and higher molecular hydrocarbons are hardly detected. At $360^{\circ} \mathrm{C}$, higher amounts of ethane and ethylene are detected for the first time. The mass fraction of propane and propylene remains below $1.5 \%$. This value increases up to $7.3 \%$ at $420{ }^{\circ} \mathrm{C}$. In general, the variation margin of the mass fraction increases with increasing temperature.

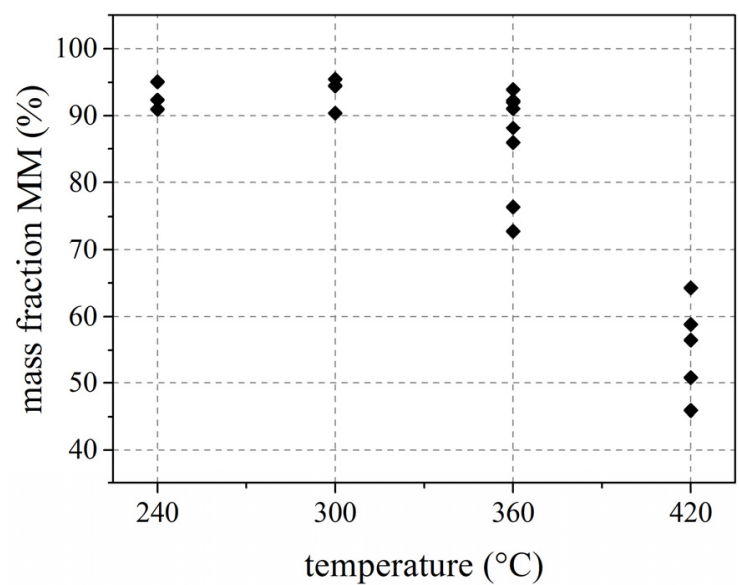

(a)

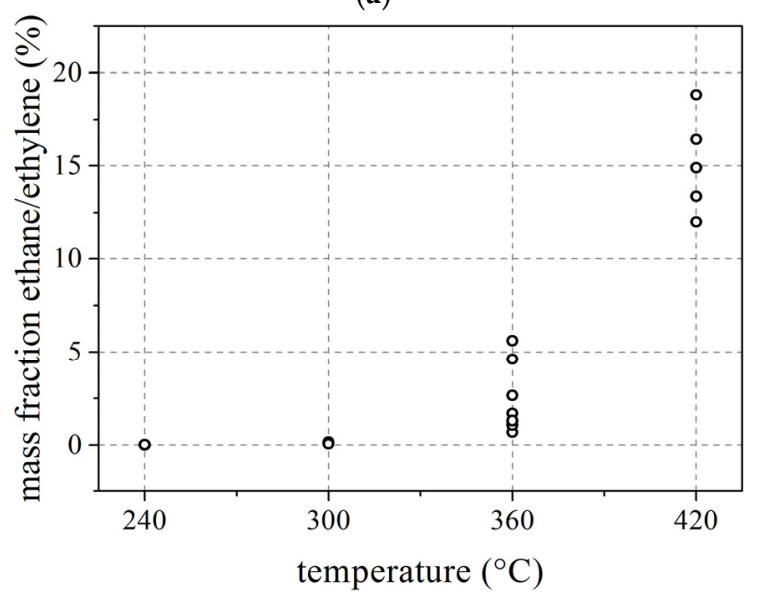

(c)

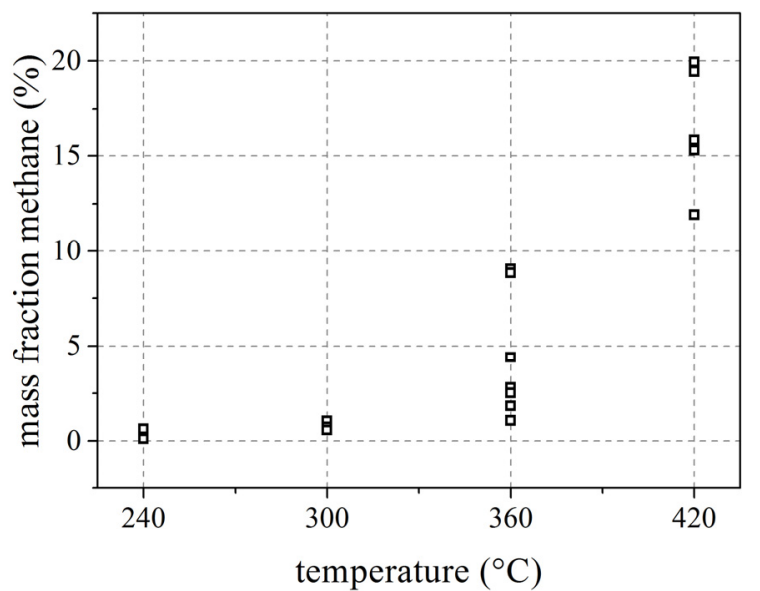

(b)

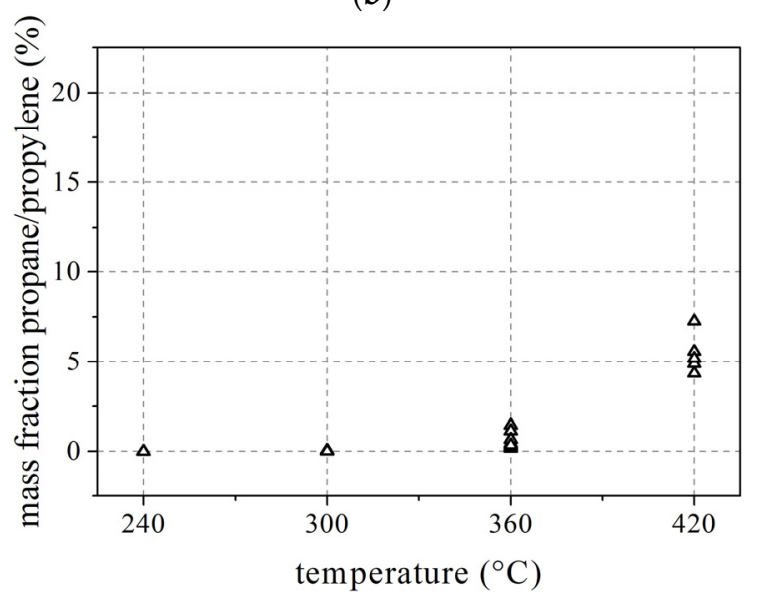

(d)

Figure 5. Mass fraction of: (a) hexamethyldisiloxane (MM); (b) methane; (c) ethane/ethylene and; and (d) propane/propylene in the vapor phase after the experiment depending on temperature $(t=72 \mathrm{~h})$.

\subsection{Influence of Time on Thermal Degradation}

In general, the retention time within an ORC evaporator is far less than $72 \mathrm{~h}$. However, due to impropriate mixing and dead volume, high residence times may occur in reality as well. Furthermore, short retention times could give knowledge about the chemical reactions involved in the degradation process. Therefore, the influence of time on the degradation is evaluated. A temperature of $420{ }^{\circ} \mathrm{C}$ is chosen to attain high degradation rates which are essential for meaningful results on the influence of time. The mass fraction of MM in Figure 6 drops and the ones of the degradation products increase with increasing time. The slope is almost linear within the first $24 \mathrm{~h}$, while, for longer times, the curves flatten. 


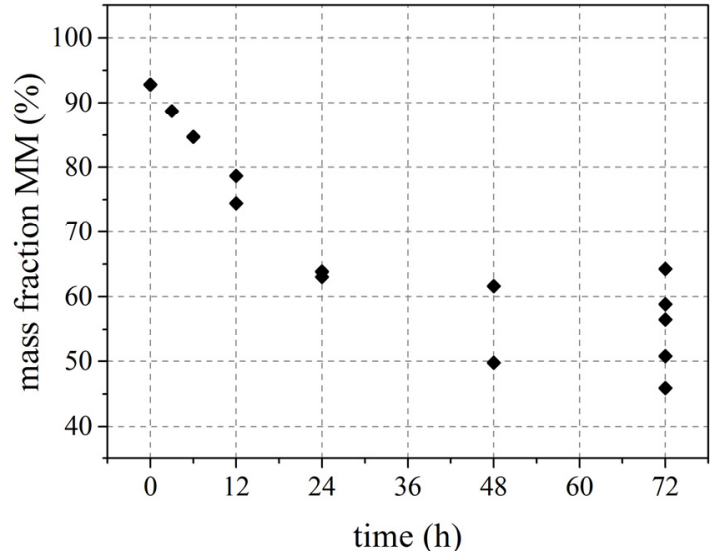

(a)

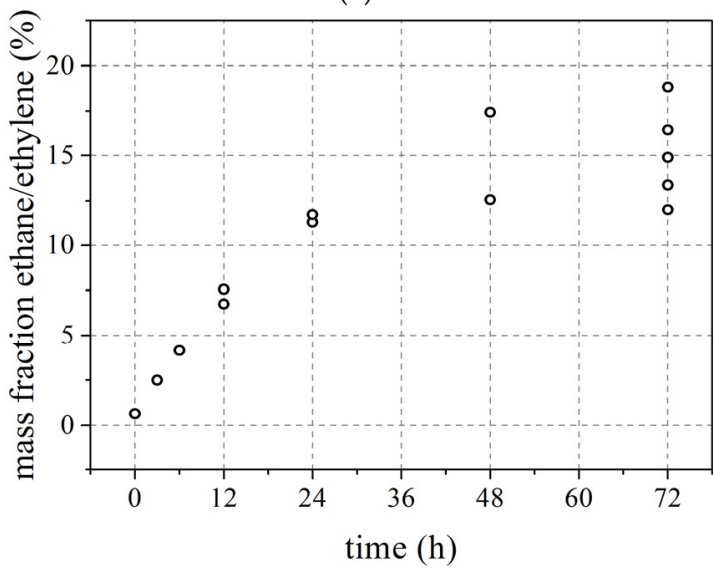

(c)

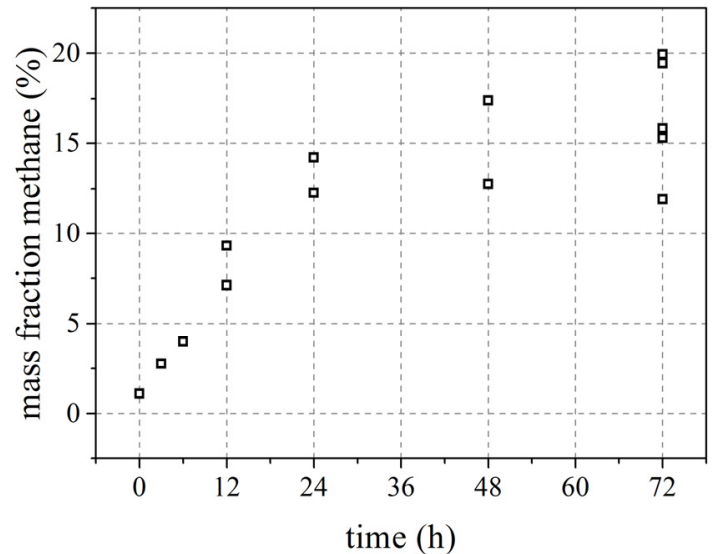

(b)

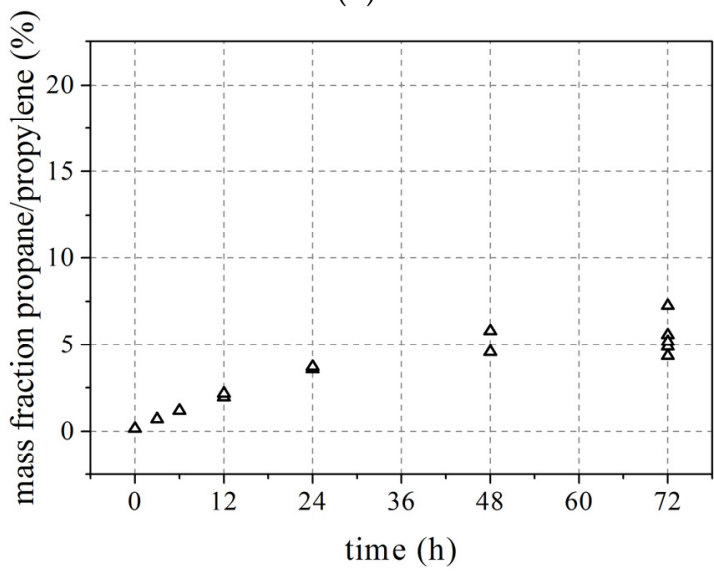

(d)

Figure 6. Mass fraction of: (a) MM; (b) methane; (c) ethane/ethylene and; and (d) propane/propylene in the vapor phase after the experiment depending on time $\left(T=420{ }^{\circ} \mathrm{C}\right)$.

\section{Materials and Methods}

\subsection{Qualitative Evaluation of Degradation Products}

The formation of C1-, C2- and C3-hydrocarbons suggests that the break of a Si-C bond and the subsequent formation of methyl radicals can be seen as the start reaction of thermal degradation. The increased variation margin above a temperature of $360{ }^{\circ} \mathrm{C}$ in Figure 5 suggests complex recombination effects that differ, especially for longer times of the experiment, and are strongly influenced by number and kind of available radicals. The theory of free radicals is also supported by the results in Figure 6. The lower the duration of the experiment, the fewer radicals are available and the straighter forward is their influence on the mass fraction especially of MM, methane and ethane/ethylene. This leads to the characteristic linear slope for times lower than $24 \mathrm{~h}$. The number and types of radicals and, therefore, the variation margin increases for longer times of the experiments. Furthermore, although the amount of free water is low, available water molecules take place in the reaction. However, as soon as all water molecules are converted, the catalytic acceleration of water on the degradation stops and the curves in Figure 6 flatten after about $24 \mathrm{~h}$.

\subsection{Quantitative Evaluation of Degradation}

The mass of gaseous MM before and after the experiment is calculated from the composition of the vapor phase. In combination with the overall mass of $\mathrm{MM}$ in the reactor, the annual degradation rate is deduced (Figure 7 ). 


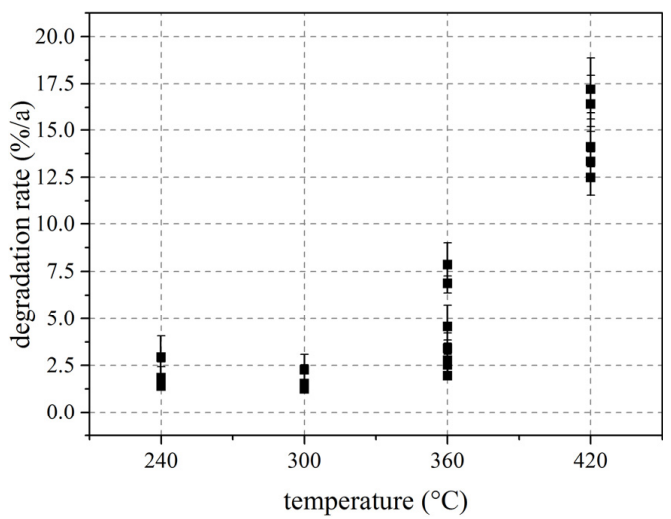

Figure 7. Degradation rate depending on temperature $(t=72 \mathrm{~h})$.

The typical exponential progression according to Arrhenius' law is observed. The absolute value for temperatures below $300{ }^{\circ} \mathrm{C}$ is mainly lower than the typical leakage rates of 3\%/a [34] that are assumed for geothermal applications. The degradation rate increases considerably for temperatures higher than $300{ }^{\circ} \mathrm{C}$. Figure 7 also gives the error-containing values for the degradation rate if the following typical errors for the input data of the calculation are assumed:

- volume of the reactor and mass of MM in the reactor, $\pm 2.0 \%$;

- mass fraction of $\mathrm{MM}$ in liquid and vapor phase, $\pm 2.0 \%$;

- density of $\mathrm{MM}$ in liquid and vapor phase, $\pm 1.0 \%$.

The dependency of the annual degradation rate on the duration of the experiments in Figure 8 shows a steep decrease for times lower than $12 \mathrm{~h}$, and subsequently the curve flattens. Note that error-containing minimum and maximum values are given again. It is obvious that the relative failure increases for lower durations of the experiment as the values are extrapolated to gain the annual degradation rate. Furthermore, according to Figure 8, the annual degradation rates that are calculated from the experiments for duration of $72 \mathrm{~h}$ (Figure 7) are probably higher in real ORC units, in which the retention time of the working fluid in the evaporator is far less. To account for this, a test series is carried out in which MM is just heated up to the pre-set temperature and instantly cooled down afterwards. Therefore, it is possible to "simulate" the heating in the evaporator and instant cooling in the turbine and condenser in an ORC unit. It is shown that the amount of low molecular hydrocarbons is low until a temperature of $300^{\circ} \mathrm{C}$ (Figure 9). At $360^{\circ} \mathrm{C}$, the mass fraction of methane increases. Subsequently, the mass fraction of ethane/ethylene and propane/propylene increases at $420^{\circ} \mathrm{C}$. This again proves the assumption that the break of a Si-C bondage and the set-free methyl radicals together with free water molecules influence the thermal degradation of MM.

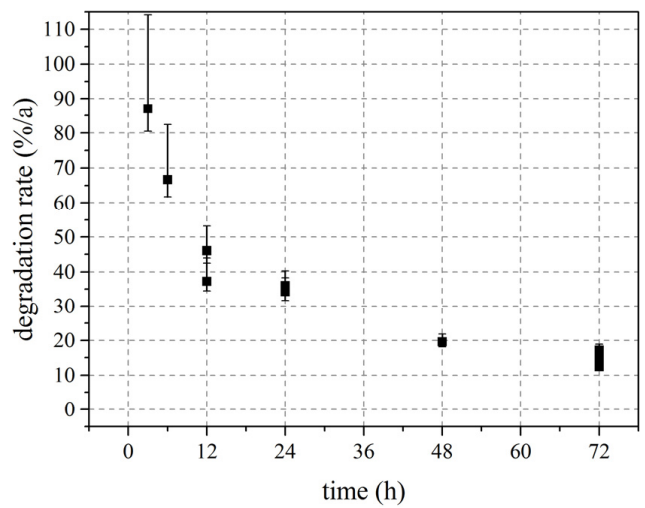

Figure 8. Degradation rate depending on time $\left(T=420^{\circ} \mathrm{C}\right)$. 


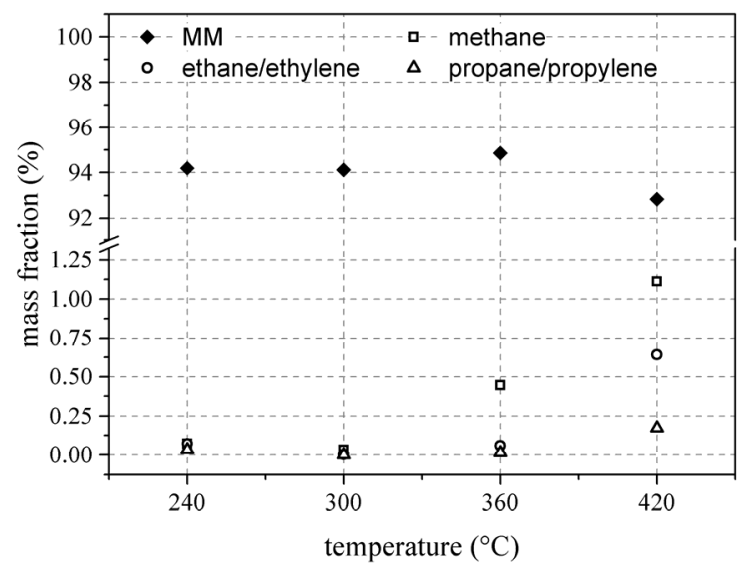

Figure 9. Mass fraction of MM, methane, ethane/ethylene and propane/propylene in the vapor phase after the experiment depending on temperature (test series: heating and instant cooling).

\subsection{Impact on the Set-Up of Organic Rankine Cycle Power Units}

From the gained results, it can be concluded that the use of MM in ORC units without intermediate thermal oil circuit is possible as long as the fluid temperature does not exceed $300^{\circ} \mathrm{C}$. Therefore, $\mathrm{MM}$ can be used for heat source temperature up to $300^{\circ} \mathrm{C}$ without any concerns. For higher heat source temperatures and constantly circulating working fluid, the thermodynamic suitable evaporation temperatures are around $240{ }^{\circ} \mathrm{C}$. Therefore, conditions below $300^{\circ} \mathrm{C}$ can be achieved if special care on evaporator design, particularly concerning film temperature and hotspots, is taken. Hence, this characteristic value should be used in simulation and design of ORC power plants and heat exchangers, whereas the value is of special interest for dynamic simulations [35].

Furthermore, Figure 9 shows that the formation of methane is an indicator for the thermal degradation. Therefore, in future ORC units a methane sensor could be placed at the top of the evaporator to give evidence on the degradation of $\mathrm{MM}$ (for example in case of unforeseen hotspots or in failure mode). The sensor could be set with a threshold value of $3 \%$ as it would be a clear indicator for degradation of the working fluid. In combination with a bleeder valve, the degradation products could be released before influencing the whole ORC system. Concerning the catalytic influence of free water in the system and the occurrence of contaminants, the approach of "boil out" during first start-up which is used for thermal oil circuits should be adapted to future ORC units based on siloxanes as working fluids. In this approach, the organic working fluid is heated up very slowly during the first start-up and evaporated water or low-molecular contaminants are released through a bleeder valve. Therefore, the siloxane is purified and, according to Figure 8, the degradation rate is much lower without free water molecules and contaminants. Note that in this study the samples already have lab-quality. In state-of-the-art power plants, the water content and the amount of contaminants can be even higher, which would explain the high degradation rates reported by Erhart et al. [15].

Lastly, to avoid hot-spots in the heat exchangers in highly dynamic operation, a spray attemperator system as it has already been proposed by Benato et al. [35] could be installed. For cyclopentane, Benato et al. [35] used a threshold value of $270{ }^{\circ} \mathrm{C}$ for controlling the attemperator system, for $\mathrm{MM}$ the results of this study leads to a value of $300^{\circ} \mathrm{C}$.

\section{Conclusions}

The thermal degradation of MM depending on temperature and time was analyzed qualitatively and quantitatively and the impact on the set-up of ORC power units was pointed out. The main results can be summarized as follows:

- The main degradation products of MM are low molecular hydrocarbons like methane, ethane/ethylene and propane/propylene. 
- The degradation rate is strongly influenced not only by the temperature but also by the retention time.

- $\mathrm{MM}$ is stable up to a temperature of $300^{\circ} \mathrm{C}$ with annual degradation rates of less than $3.5 \%$.

- Methane can be used as indicator for ongoing thermal degradation of MM.

- The design of direct contact evaporators based on MM requires special care concerning film temperature and avoiding hot spots in the evaporator.

- Free water molecules and contaminants may influence the degradation rates significantly and, therefore, a special start-up procedure including a boil-out of those substances is necessary.

- Thermal stability can be included as parameter in ORC working fluid database and the maximum temperature can be used as boundary condition for ORC design and simulation.

Ongoing and future work will include the comparison with other linear siloxanes (octamethyltrisiloxane (MDM) and decamethyltetrasiloxane (MD2M)). Furthermore, a dynamic test rig including pump, preheater, evaporator, superheater, throttle valve and condenser is planned to account for mechanical stress of the working fluid due to the cycle as well.

Acknowledgments: The authors gratefully acknowledge financial support of the Bayerische Staatsministerium für Bildung und Kultus, Wissenschaft und Kunst within the framework TechnologieAllianzOberfranken. This publication was funded by the German Research Foundation (DFG) and the University of Bayreuth in the funding programme Open Access Publishing.

Author Contributions: All authors contributed to this work by collaboration. Markus Preißinger is the main author of this manuscript. Dieter Brüggemann supervised the project. All authors revised and approved the publication.

Conflicts of Interest: The authors declare no conflict of interest.

\section{Abbreviations}

The following abbreviations are used in this manuscript:

$\begin{array}{ll}\text { C } & \text { Carbon } \\ \text { MDM } & \text { Octamethyltrisiloxane } \\ \text { MD2M } & \text { Decamethyltetrasiloxane } \\ \text { MM } & \text { Hexamethyldisiloxane } \\ \text { ORC } & \text { Organic Rankine cycle } \\ \mathrm{Si} & \text { Silicon } \\ t & \text { Time } \\ T & \text { Temperature }\end{array}$

\section{References}

1. Obernberger, I.; Thornhofer, P.; Reisenhofer, E. Description and evaluation of the new $1000 \mathrm{kWel}$ Organic Rankine Cycle process integrated in the biomass CHP plant in Lienz, Austria. Euroheat Power 2002, 10, 18-25.

2. Obernberger, I. Decentralized biomass combustion: State of the art and future development. Biomass Bioenergy 1998, 14, 33-56. [CrossRef]

3. Preißinger, M.; Heberle, F.; Brüggemann, D. Thermodynamic analysis of double-stage biomass fired Organic Rankine Cycle for micro-cogeneration. Int. J. Energy Res. 2012, 36, 944-952. [CrossRef]

4. Mang, T.; Dresel, W. Lubricants and Lubrication, 2nd ed.; Wiley-VCH: Weinheim, Germany, 2007.

5. Yang, K.; Zhang, H.; Song, S.; Yang, F.; Liu, H.; Zhao, G.; Zhang, J.; Yao, B. Effects of Degree of Superheat on the Running Performance of an Organic Rankine Cycle (ORC) Waste Heat Recovery System for Diesel Engines under Various Operating Conditions. Energies 2014, 7, 2123-2145. [CrossRef]

6. Yang, K.; Zhang, H.; Song, S.; Zhang, J.; Wu, Y.; Zhang, Y.; Wang, H.; Chang, Y.; Bei, C. Performance Analysis of the Vehicle Diesel Engine-ORC Combined System Based on a Screw Expander. Energies 2014, 7, 3400-3419. [CrossRef]

7. Zhang, C.; Shu, G.; Tian, H.; Wei, H.; Liang, X. Comparative study of alternative ORC-based combined power systems to exploit high temperature waste heat. Energy Convers. Manage. 2015, 89, 541-554. [CrossRef] 
8. Camporeale, S.M.; Pantaleo, A.M.; Ciliberti, P.D.; Fortunato, B. Cycle configuration analysis and techno-economic sensitivity of biomass externally fired gas turbine with bottoming ORC. Energy Convers. Manag. 2015, 105, 1239-1250. [CrossRef]

9. Chowdhury, J.; Nguyen, B.; Thornhill, D. Modelling of Evaporator in Waste Heat Recovery System using Finite Volume Method and Fuzzy Technique. Energies 2015, 8, 14078-14097. [CrossRef]

10. Guillen, D.; Klockow, H.; Lehar, M.; Freund, S.; Jackson, J. Development of a Direct Evaporator for the Organic Rankine Cycle. In Energy Technology 2011; Neelameggham, N.R., Belt, C.K., Jolly, M., Reddy, R.G., Yurko, J.A., Eds.; John Wiley \& Sons, Inc.: Hoboken, NJ, USA, 2011; pp. 25-35.

11. Bei, C.; Zhang, H.; Yang, F.; Song, S.; Wang, E.; Liu, H.; Chang, Y.; Wang, H.; Yang, K. Performance Analysis of an Evaporator for a Diesel Engine-Organic Rankine Cycle (ORC) Combined System and Influence of Pressure Drop on the Diesel Engine Operating Characteristics. Energies 2015, 8, 5488-5515. [CrossRef]

12. Weith, T.; Heberle, F.; Preißinger, M.; Brüggemann, D. Performance of Siloxane Mixtures in a High-Temperature Organic Rankine Cycle Considering the Heat Transfer Characteristics during Evaporation. Energies 2014, 7, 5548-5565. [CrossRef]

13. Colonna, P.; Casati, E.; Trapp, C.; Mathijssen, T.; Larjola, J.; Turunen-Saaresti, T.; Uusitalo, A. Organic Rankine Cycle Power Systems: From the Concept to Current Technology, Applications, and an Outlook to the Future. J. Eng. Gas Turbines Power 2015, 137. [CrossRef]

14. Di Nanno, L.R.; Di Bella, F.A.; Koplow, M.D. An RC-1 Organic Rankine Bottoming Cycle for an Adiabatic Diesel Engine; Technical Report, DOE/NASA/0302-1; Nasa Lewis Research Center: Cleveland, OH, USA, 1983.

15. Erhart, T.; Gölz, J.; Eickler, U.; Van Den Broek, M. Fluid stability in large scale ORCs using siloxanes-long-term experiences and fluid recycling. In Proceedings of the 3rd International Seminar on ORC Power Systems, ASME-ORC 2015, Brussels, Belgium, 12-14 October 2015.

16. Colonna, P.; Nannan, N.; Guardone, A.; Lemmon, E. Multiparameter equations of state for selected siloxanes. Fluid Phase Equilib. 2006, 244, 193-211. [CrossRef]

17. Angelino, G. Cyclic Methylsiloxanes as Working Fluids for Space Power Cycles. J. Sol. Energy Eng. 1993, 115, 130-137. [CrossRef]

18. Dvornic, P.R. Thermal properties of polysiloxanes. In Silicon Containing Polymers: The Science and Technology of Their Synthesis and Applications; Jones, R.G., Ed.; Kluwer Acad. Publ.: Dordrecht, The Netherlands, 2000; pp. 185-212.

19. Dvornic, P.R. High temperature stability of cyclosiloxanes. In Silicon Compounds: Silanes and Silicones: A Survey of Properties and Chemistry, 2nd ed.; Gelest Inc.: Morrisville, PA, USA, 2008; pp. 441-454.

20. Ginosar, D.M.; Petkovic, L.M.; Guillen, D.P. Thermal Stability of Cyclopentane as an Organic Rankine Cycle Working Fluid. Energy Fuels 2011, 25, 4138-4144. [CrossRef]

21. Sealed Glass Tube Method to Test the Chemical Stability of Materials for Use within Refrigerant Systems; American Society of Heating, Refrigerating and Air-Conditioning Engineers, Inc.: Atlanta, GA, USA, 2007.

22. Buravtsev, N.; Grigorev, A.; Kolbanovskii, Y.; Ovsyannikov, A. Thermal and thermooxidative stability of ozone-safe freons. Russ. J. Org. Chem. 1994, 30, 1880-1890.

23. Grassie, N.; Macfarlane, I. The thermal degradation of polysiloxanes-I. Poly(dimethylsiloxane). Eur. Polym. J. 1978, 14, 875-884. [CrossRef]

24. Grassie, N.; Macfarlane, I.; Francey, K. The thermal degradation of polysiloxanes-II. Poly(methylphenylsiloxane). Eur. Polym. J. 1979, 15, 415-422. [CrossRef]

25. Deshpande, G.; Rezac, M.E. Kinetic aspects of the thermal degradation of poly(dimethyl siloxane) and poly(dimethyl diphenyl siloxane). Polym. Degrad. Stab. 2002, 76, 17-24. [CrossRef]

26. Zhou, W.; Yang, H.; Guo, X.; Lu, J. Thermal degradation behaviors of some branched and linear polysiloxanes. Polym. Degrad. Stab. 2006, 91, 1471-1475. [CrossRef]

27. Kuramochi, H.; Imai, F.; Kondoh, H.; Kunimori, K.; Uchijima, T.; Nozoye, H. Decomposition of cyclopentane on Ni(755): Peculiar decomposition behavior of cyclopentane. Surf. Sci. 1993, 287-288, 217-221.

28. Angelino, G.; Invernizzi, C.M.; Macchi, E. Organic working fluid optimization for space power cycles. In Modern Research Topics in Aerospace Propulsion: In honor of Corrado Casci; Angelino, G., Ed.; Springer: New York, NY, USA, 1991; pp. 297-326.

29. Calderazzi, L.; Di Paliano, P.C. Thermal stability of R-134a, R-141b, R-13I1, R-7146, R-125 associated with stainless steel as a containing material. Int. J. Refrig. 1997, 20, 381-389. [CrossRef] 
30. Pasetti, M.; Invernizzi, C.M.; Iora, P. Thermal stability of working fluids for organic Rankine cycles: An improved survey method and experimental results for cyclopentane, isopentane and $n$-butane. Appl. Therm. Eng. 2014, 73, 764-774. [CrossRef]

31. Lasala, S.; Invernizzi, C.; Iora, P.; Chiesa, P.; Macchi, E. Thermal Stability Analysis of Perfluorohexane. Energy Procedia 2015, 75, 1575-1582. [CrossRef]

32. Stephan, P.; Mayinger, F.; Schaber, K.; Stephan, K. Thermodynamik: Grundlagen und Technische Anwendungen; Band 1: Einstoffsysteme, 18th ed.; Springer: Berlin/Heidelberg, Germany, 2009.

33. Manders, W.F.; Bellama, J.M. Multiphoton infrared laser-induced degradation of polydimethylsiloxane and hexamethyldisiloxane. J. Polym. Sci. Polym. Chem. Ed. 1985, 23, 351-357. [CrossRef]

34. Heberle, F.; Brüggemann, D.; Obermeier, A. Mögliche Emissionen bei der Strom- und Wärmeerzeugung aus Geothermie durch den Einsatz von F-Gasen im Energiewandlungsprozess mittels ORC; Climate Change 16/2012; Umweltbundesamt: Dessau-Roßlau, Germany, 2012. (In German)

35. Benato, A.; Kærn, M.R.; Pierobon, L.; Stoppato, A.; Haglind, F. Analysis of hot spots in boilers of organic Rankine cycle units during transient operation. Appl. Energy 2015, 151, 119-131. [CrossRef]

(C) 2016 by the authors; licensee MDPI, Basel, Switzerland. This article is an open access article distributed under the terms and conditions of the Creative Commons by Attribution (CC-BY) license (http://creativecommons.org/licenses/by/4.0/). 